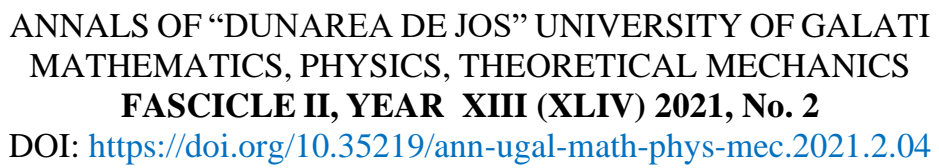

\title{
Risk to the health of agricultural equipment drivers in Romania caused by exposure to vibration and noise
}

\author{
Mihaela Picu, ${ }^{1, *}$ \\ ${ }^{1}$ Faculty of Engineering and Agronomy in Braila, ,,Dunărea de Jos” University of Galati, Romania \\ *Corresponding author: mihaelapicu@yahoo.com
}

\begin{abstract}
In this paper, the exposures to vibrations transmitted to the whole body and to the noises of tractors were studied. The determinations took place in the largest agricultural region of Romania, in Bărăgan, namely, in the Brăila Plain. Two types of tractors were analyzed: one from 1993 and one from 2013, with 5500h of operation. Accelerations transmitted to humans with MAESTRO 01dB and noise were measured with the Blue Solo sound level meter (01 dB-Metravib). Comfort Note have been calculated. For the 1993 tractor, the total acceleration r.m.s. has values between $[4.366 \div 6.389] \mathrm{m} / \mathrm{s}^{2}$, exceeding $3.216 \div 5.556$ times the daily exposure limit value, and from the Comfort Note, it is found that the situation is extremely uncomfortable. Extremely uncomfortable; the average sound level is $95.5 \mathrm{~dB}(\mathrm{~A})$, exceeding exposure limit values. For the 2013 tractor, the total acceleration r.m.s. has values between $[0.6696 \div 1.6525] \mathrm{m} / \mathrm{s}^{2}$, slightly exceeding the daily exposure limit value, and from the Comfort Note, it is found that the situation is between slightly uncomfortable and uncomfortable; the average sound level is $65.9 \mathrm{~dB}(\mathrm{~A})$, lower than the lower exposure action values. For this reason, the stock of agricultural equipment needs to be renewed, but this is particularly difficult, given that their prices range from several tens of thousands of euros to hundreds of thousands of euros.
\end{abstract}

Keywords: whole body vibrations, noise, Comfort Note, tractor.

\section{INTRODUCTION}

Although we are in the $21^{\text {st }}$ century, agriculture in Romania has not been modernized everywhere, especially due to the lack of money of individual farmers. Hence, the numerous threats posed to people's health, even today.

An important role in agriculture is played by the equipment for farming the land, and those who drive this machinery are subjected to various stressors: vibrations, noises, high temperatures, dust, etc.

Several researchers have studied the combined effects of noise and heat on people's performance in the workplace. For example, a number of subjects were subjected to noises of 38 $\mathrm{dB}(\mathrm{A})$ and $53 \mathrm{~dB}(\mathrm{~A})$ and temperatures of $19^{\circ} \mathrm{C}$ and $27^{\circ} \mathrm{C}$ for 38 hours [1]. They were then given a range of tasks to achieve, among which: working with mental arithmetic, a recognition task, hidden geometric figures, proofreading, verbal fluency, and the five-choice serial reaction task. The results of the tests showed that the quality of human performance decreases as the level of stressors increases.

Further experiments were performed on 16 subjects who were exposed to noises of $35 \mathrm{~dB}(\mathrm{~A})$ and $65 \mathrm{~dB}(\mathrm{~A})$ and temperatures of $22^{\circ} \mathrm{C}, 26^{\circ} \mathrm{C}$, and $30^{\circ} \mathrm{C}$ for 3 hours [2]. It was found that as the temperature rises, people begin to experience irritation of the nose and throat, headaches, muddled thinking, and lower performance. On the other hand, louder noise led to fatigue and impaired power of concentration. Interestingly, most subjects were reported to find heat more tolerable than noise. 
Another set of experiments was carried out on 18 subjects subjected to noises of $35 \mathrm{~dB}(\mathrm{~A}), 60$ $\mathrm{dB}(\mathrm{A})$ and $75 \mathrm{~dB}(\mathrm{~A})$ and temperatures of $18^{\circ} \mathrm{C}, 24^{\circ} \mathrm{C}$, and $30^{\circ} \mathrm{C}$ [3], for $30 \mathrm{~min}$ and $120 \mathrm{~min}$.

Table 1. Symptoms of vibration exposure at frequencies in the range $1 \div 20 \mathrm{~Hz}$ (ISO 2631)

\begin{tabular}{|l|c|}
\hline Symptoms & $\boldsymbol{v}(\mathbf{H z})$ \\
\hline General discomfort & $4-9$ \\
\hline Headaches & $13-20$ \\
\hline Jaw pain & $6-8$ \\
\hline Speech deficiencies & $13-20$ \\
\hline Difficult breathing & $12-16$ \\
\hline Chest pain & $5-7$ \\
\hline Abdominal pain & $4-10$ \\
\hline Urination problems & $10-18$ \\
\hline Increased muscle tone & $13-20$ \\
\hline Difficulty of movement & $4-8$ \\
\hline Muscle contraction & $4-9$ \\
\hline
\end{tabular}

The combined effect of these two stressors manifested itself in the form of discomfort, as well as reduced human performance (Tab. 1).

The negative effect of vibrations transmitted to operators by equipment in motion has been studied by many researchers [4-13].

Newell and Mansfield (2008) [14] found, in a group of 21 subjects subjected to $1 \div 20 \mathrm{~Hz}$ vibration and placed in various positions (upright, twisted, with and without armrests) that the quality of their work performance dropped significantly, their response time increased, and the amount of work input decreased. The addition of the armrest resulted in improving the working conditions, and, implicitly, the quality of performance.

\section{MATERIALS AND METHODS}

The determinations took place in the largest agricultural region of Romania, Bărăgan (Fig. 1), in the Brăila Plain (Fig. 2), in the red colored area. The Bărăgan Plain in southeastern Romania is a plain known for its black soil and rich humus content, as well as for the steppe vegetation due to the particularly harsh climate: hot and dry summers; very frosty winters with gusts of wind). The plain of Brăila or Bărăganul de Nord represents the northeastern section of Bărăgan, typically made up of smooth fields, with an altitude of between $20-50 \mathrm{~m}$, which have their origin in fluvio-lacustrine cones, covered with a thick blanket of loess [15].

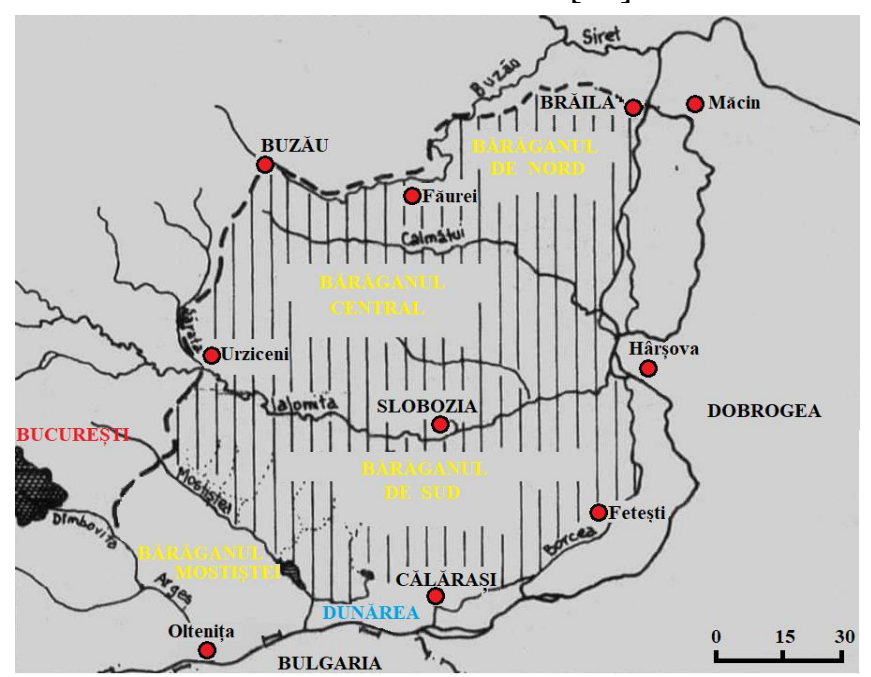

Fig. 1. Bărăgan Plain [16]

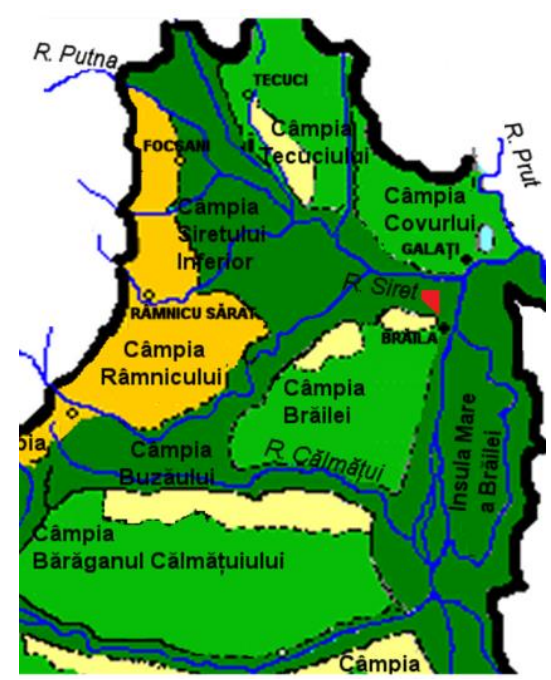

Fig. 2. Brăila Plain [17]

The noise was measured with the Blue Solo sound level meter (01dB-Metravib); this sound level meter (Fig. 3) can perform: noise level measurement in octave (1/1) or third octave (1/3) spectrum, T60 reverberation time measurement, real-time signal acquisition, large storage memory (2GB SDcard). The noise was analyzed with dBTRAIT, a software used for calculating, evaluating, and monitoring noise. 
The vibrations transmitted to humans were measured with a MAESTRO $01 \mathrm{~dB}$ vibrometer. This can perform measurements for the whole body up to $0.4 \mathrm{~Hz}$. It uses the PAD triaxial accelerometer to measure the vibrations transmitted to the whole body WBV by placing it under the backside (Fig. 4).

Noise and vibration levels were analyzed on 2 types of tractors:

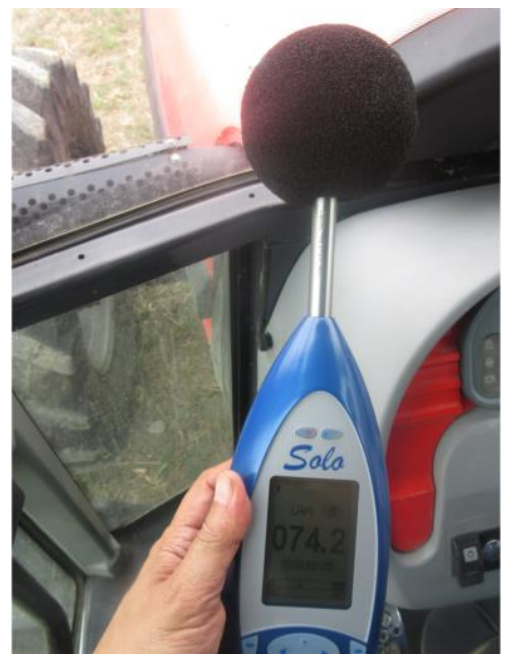

Fig. 3. Blue Solo Sonometer

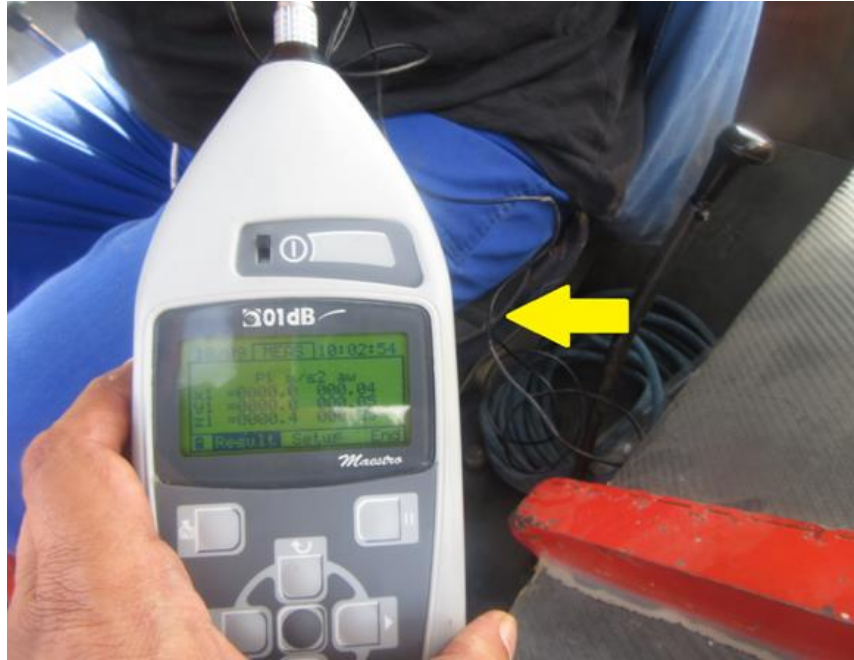

Fig. 4. WBV Measurement $(\prec$ triaxial PAD accelerometer)

a) The 1993 tractor, with rear-wheel drive and an initial power of 65HP, has declined over time. In summer, the temperature is extremely high, due to the engine, which "pushes" the hot air into the cabin through some blades. Also, the noise is unbearable and the vibrations are extremely high.

b) The 2013 tractor, with $5500 \mathrm{~h}$ of operation, with a very large engine block $\left(1400 \mathrm{~cm}^{3}\right)$. In summer, the temperature is reasonable because the air is "pushed" down or sideways and it is equipped with air conditioning. All areas are sealed, so the noise is very low and the vibrations are small (but these also depend on the condition of the soil: if the soil is rocky after the first plowing, the vibrations will be higher).

All determinations were made in accordance with the legislation in force at national and European levels [18-27]. (Table 2).

Table 2. Daily exposure limit and whole body vibration action values as specified in the EU Vibration Directive (2002/44)

\begin{tabular}{|c|c|}
\hline Exposure action value (EAV) & Exposure limit value (ELV) \\
\hline $0.5 \mathrm{~m} / \mathrm{s}^{2} \mathrm{~A}(8)$ r.m.s. & $1.15 \mathrm{~m} / \mathrm{s}^{2} \mathrm{~A}(8)$ r.m.s. \\
\hline
\end{tabular}

Many of the methods presented so far have not taken into account the duration of exposure; in this regard, Genser et al, (2021) [28] defined the Comfort Note for Drivers of vehicles and agricultural equipment (Tab. 3):

$$
\mathrm{NC}=10^{\mathrm{Z}}
$$

where $Z_{2}$ and $Z_{1}$ are empirically defined below:

$$
\begin{gathered}
\mathrm{Z}_{2}=(1) \frac{-0.06 \mathrm{Z}_{1}^{2}+1.6 \mathrm{Z}_{1}+0.084396}{\mathrm{Z}_{1}-0.7033} \\
\mathrm{Z}_{1}=\lg \left(\mathrm{A}_{\mathrm{w}}\right)
\end{gathered}
$$

The values on each axis are summed, giving the total acceleration r.m.s. weighted:

$$
\mathrm{A}_{\mathrm{w}}=\sqrt{\left(\mathrm{k}_{\mathrm{x}}^{2} \cdot \mathrm{a}_{\mathrm{wx}}^{2}\right)+\left(\mathrm{k}_{\mathrm{y}}^{2} \cdot \mathrm{a}_{\mathrm{wy}}^{2}\right)+\left(\mathrm{k}_{\mathrm{z}}^{2} \cdot \mathrm{a}_{\mathrm{wz}}^{2}\right)}
$$

where $\mathrm{a}_{\mathrm{wx} / \mathrm{y} / \mathrm{z}}$ are the accelerations of r.m.s. weighted on the 3 axes, and the multiplication factors are $\mathrm{k}_{\mathrm{x}}=\mathrm{k}_{\mathrm{y}}=1.4$, and $\mathrm{k}_{\mathrm{z}}=1$ (if the subject is sitting on the chair, according to ISO 2631 [19]). 
The Directive 2002/44/EC [27] stipulates the limits for whole-body vibration:

(a) the daily exposure limit value standardised to an eight-hour reference period shall be $1.15 \mathrm{~m} / \mathrm{s}^{2}$;

(b) the daily exposure action value standardised to an eight-hour reference period shall be $0.5 \mathrm{~m} / \mathrm{s}^{2}$.

Table 3. Threshold levels for $\mathrm{A}_{\mathrm{w}}$

\begin{tabular}{|c|l|}
\hline Acceleration magnitude & \multicolumn{1}{c|}{ Discomfort level } \\
\hline $\mathrm{A}_{\mathrm{w}}<0.315 \mathrm{~m} / \mathrm{s}^{2}$ & Not uncomfortable (NU) \\
\hline $0.315 \mathrm{~m} / \mathrm{s}^{2}<\mathrm{A}_{\mathrm{w}}<0.63 \mathrm{~m} / \mathrm{s}^{2}$ & Little uncomfortable (LU) \\
\hline $0.50 \mathrm{~m} / \mathrm{s}^{2}<\mathrm{A}_{\mathrm{w}}<1 \mathrm{~m} / \mathrm{s}^{2}$ & Fairly uncomfortable (FU) \\
\hline $0.80 \mathrm{~m} / \mathrm{s}^{2}<\mathrm{A}_{\mathrm{w}}<1.60 \mathrm{~m} / \mathrm{s}^{2}$ & Uncomfortable $(\mathrm{U})$ \\
\hline $1.25 \mathrm{~m} / \mathrm{s}^{2}<\mathrm{A}_{\mathrm{w}}<2.50 \mathrm{~m} / \mathrm{s}^{2}$ & Very uncomfortable (VU) \\
\hline $\mathrm{A}_{\mathrm{w}}>2 \mathrm{~m} / \mathrm{s}^{2}$ & Extremely uncomfortable (EU) \\
\hline
\end{tabular}

The Directive 2003/10/EC [26] stipulates the limits for noise level: (a) exposure limit values: $\mathrm{L}_{\mathrm{EX}, 8 \mathrm{~h}}=87 \mathrm{~dB}(\mathrm{~A})$;

(b) upper exposure action values: $\mathrm{L}_{\mathrm{EX}, 8 \mathrm{~h}}=85 \mathrm{~dB}(\mathrm{~A})$;

(c) lower exposure action values: $\mathrm{L}_{\mathrm{EX}, 8 \mathrm{~h}}=80 \mathrm{~dB}(\mathrm{~A})$.

\section{RESULTS AND DISCUSSION}

A) In the case of the 1993 tractor, the results of the determinations are presented in Fig. 5, 6, 7 and 8 .

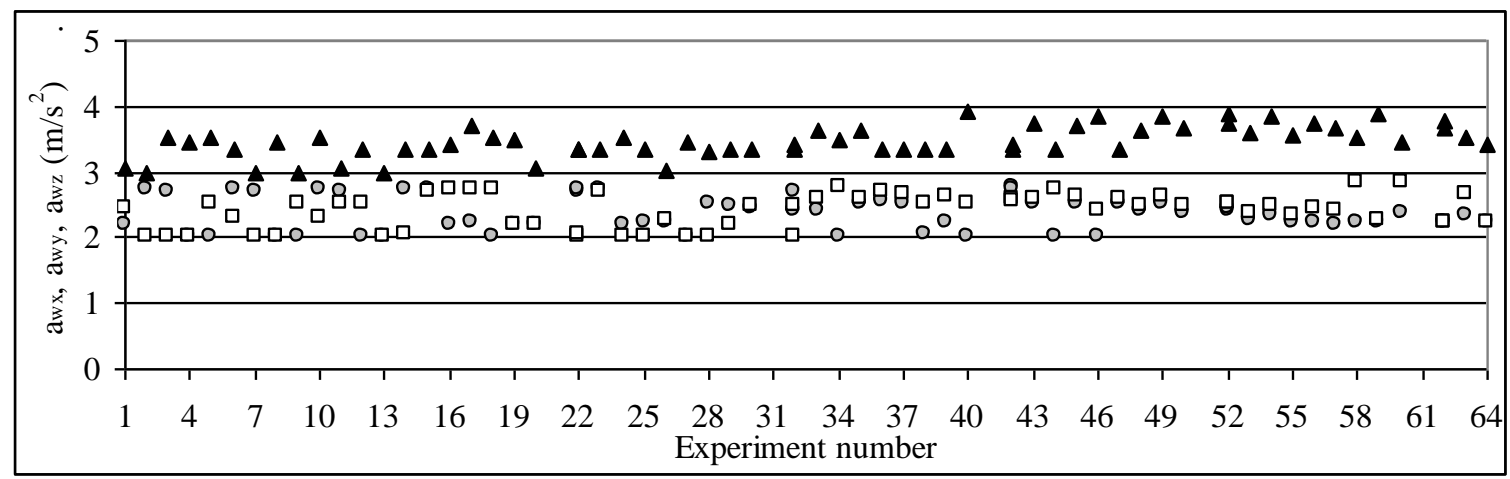

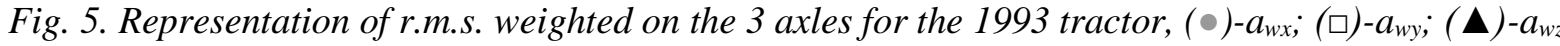

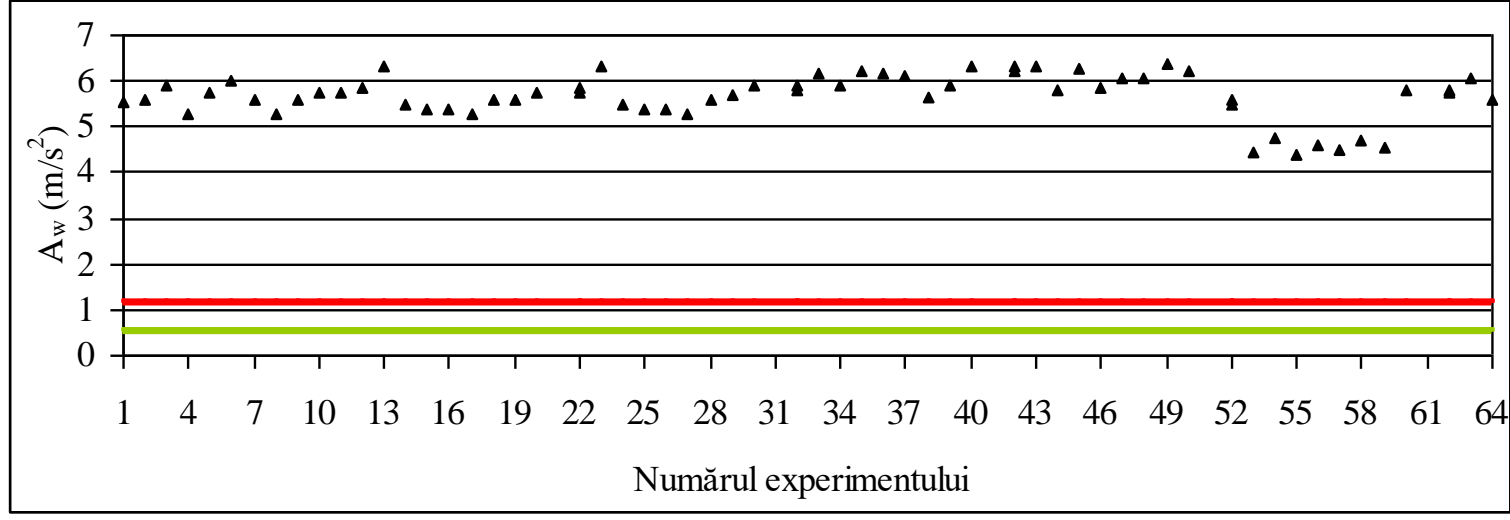

Fig. 6. Representation of the total acceleration r.m.s. weighted for the 1993 tractor (-) the daily exposure action value standardised to an eight-hour (—) the daily exposure limit value standardised to an eight-hour

From Fig. 5 it can be seen that the values of the accelerations r.m.s. weighted on the 3 axles for the 1993 tractor are as follows: $\mathrm{a}_{\mathrm{wx}} \in[2 \div 2.77] \mathrm{m} / \mathrm{s}^{2} ; \mathrm{a}_{\mathrm{wy}} \in[2 \div 2.856] \mathrm{m} / \mathrm{s}^{2} ; \mathrm{a}_{\mathrm{wz}} \in[3 \div 3.933] \mathrm{m} / \mathrm{s}^{2}$ (these are extremely high values).

From Fig. 6 it can be seen that the total acceleration r.m.s. weighted for the 1993 tractor has values between $[4.366 \div 6.389] \mathrm{m} / \mathrm{s}^{2}$, exceeding $3.216 \div 5.556$ times the daily exposure limit value (Directive 2002/44/EC [27]).

From Fig. 7 it can be seen that Comfort Note mentions values between 3.7732 and 4.4826 and, according to Table 3 , if $A_{w}>2 \mathrm{~m} / \mathrm{s}^{2}$, the situation is extremely uncomfortable. 
Regarding the noise produced by the 1993 tractor, the noise level is higher than the exposure limit values: $\mathrm{L}_{\mathrm{EX}, 8 \mathrm{~h}}=87 \mathrm{~dB}$ (A) (Fig. 8).

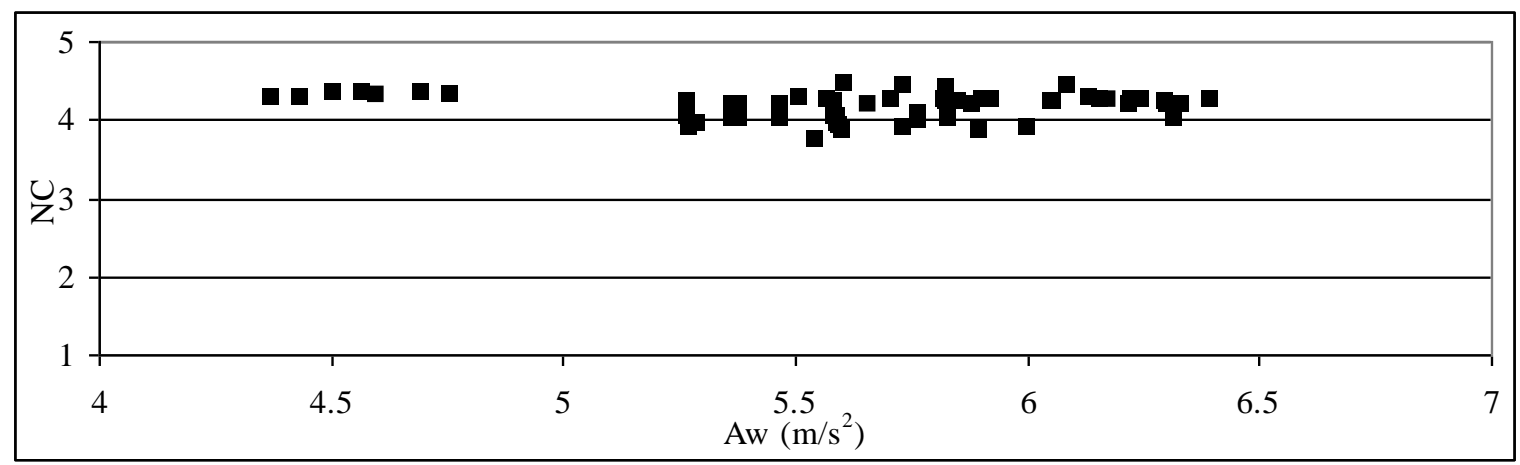

Fig. 7. Representation of the Comfort Note for the 1993 tractor

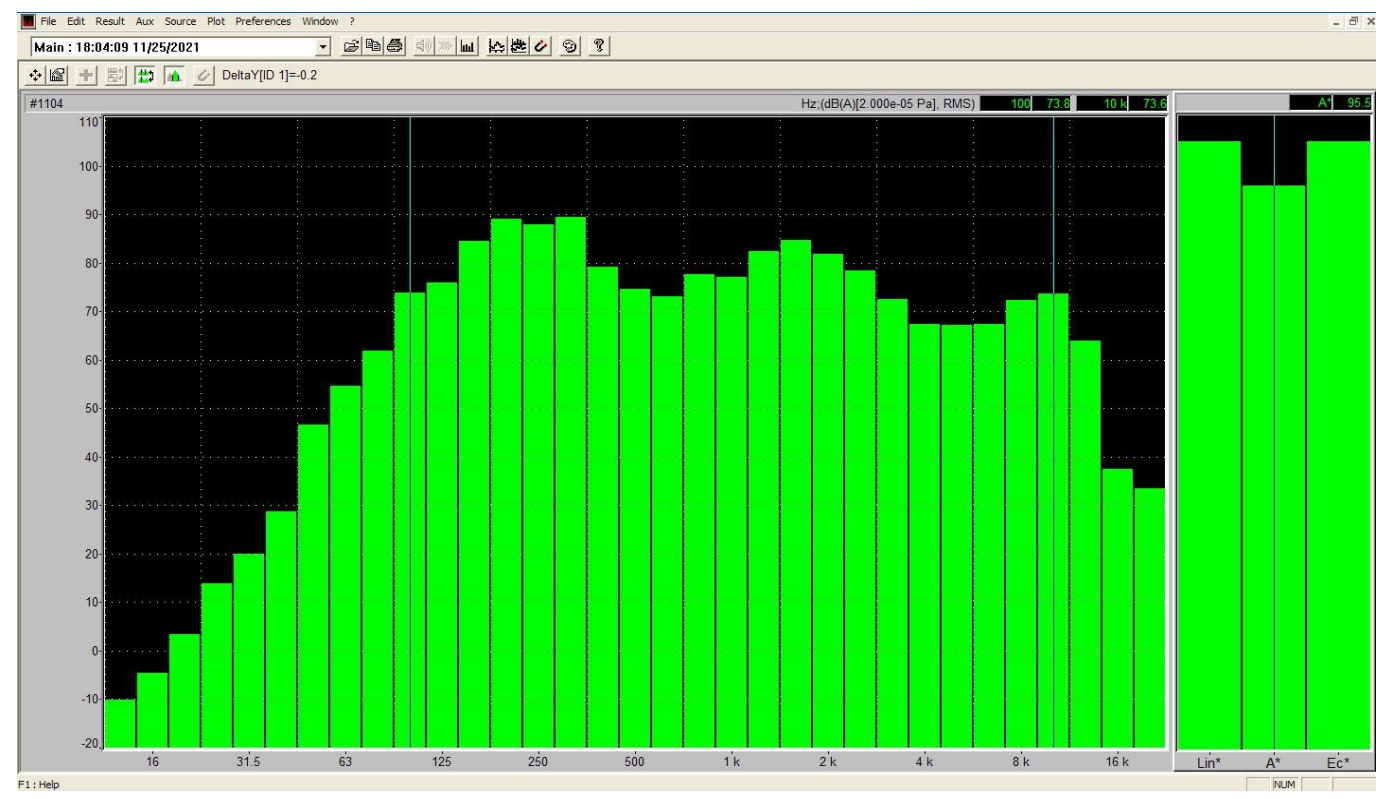

Fig. 8. Spectral sound analysis for the 1993 tractor

Fig. 8 shows the spectral distribution of the measured noise for the 1993 tractor. The sliders are placed at $100 \mathrm{~Hz}$, where the sound level is $73.8 \mathrm{~dB}(\mathrm{~A})$ and at $10 \mathrm{kHz}$, where the sound level is 73.6 $\mathrm{dB}(\mathrm{A})$. For this frequency range, the average sound level is $95.5 \mathrm{~dB}(\mathrm{~A})$, exceeding the exposure limit values (Directive 2003/10/EC [26]).

B) In the case of the 2013 tractor, the results of the determinations are shown in Fig. 9, 10, 11, 12.

From Fig. 9 it can be seen that the values of the accelerations r.m.s. weighted on the 3 axles for the 2013 tractor are included as follows: $a_{w x} \in[0.21 \div 0.77] \mathrm{m} / \mathrm{s}^{2} ; \quad a_{w y} \in[0.312 \div 0.845] \mathrm{m} / \mathrm{s}^{2}$; $\mathrm{a}_{\mathrm{wz}} \in[0,101 \div 0.903] \mathrm{m} / \mathrm{s}^{2}$ (these are values below the permissible limits).

Fig. 10 shows that the total acceleration r.m.s. weighted for the 2013 tractor has values between $[0.6696 \div 1.6525] \mathrm{m} / \mathrm{s}^{2}$; out of a total of 64 determinations, 22 are less than $1.15 \mathrm{~m} / \mathrm{s}^{2}(34.375 \%)$. The maximum value exceeds the daily exposure limit value by 1,436 times (Directive 2002/44/EC [27]). 


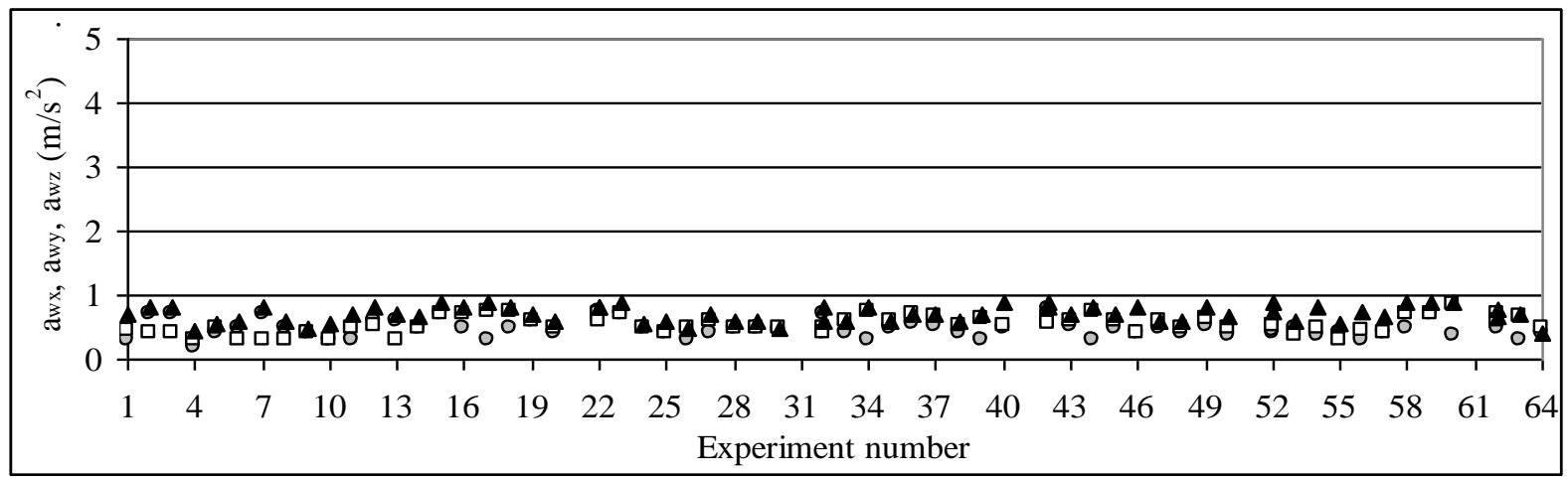

Fig. 9. Representation of accelerations r.m.s. weighted on the 3 axles for the 2013 tractor $(\bullet)-a_{w x} ;(\square)-a_{w y} ;(\mathbf{\Delta})-a_{w z}$

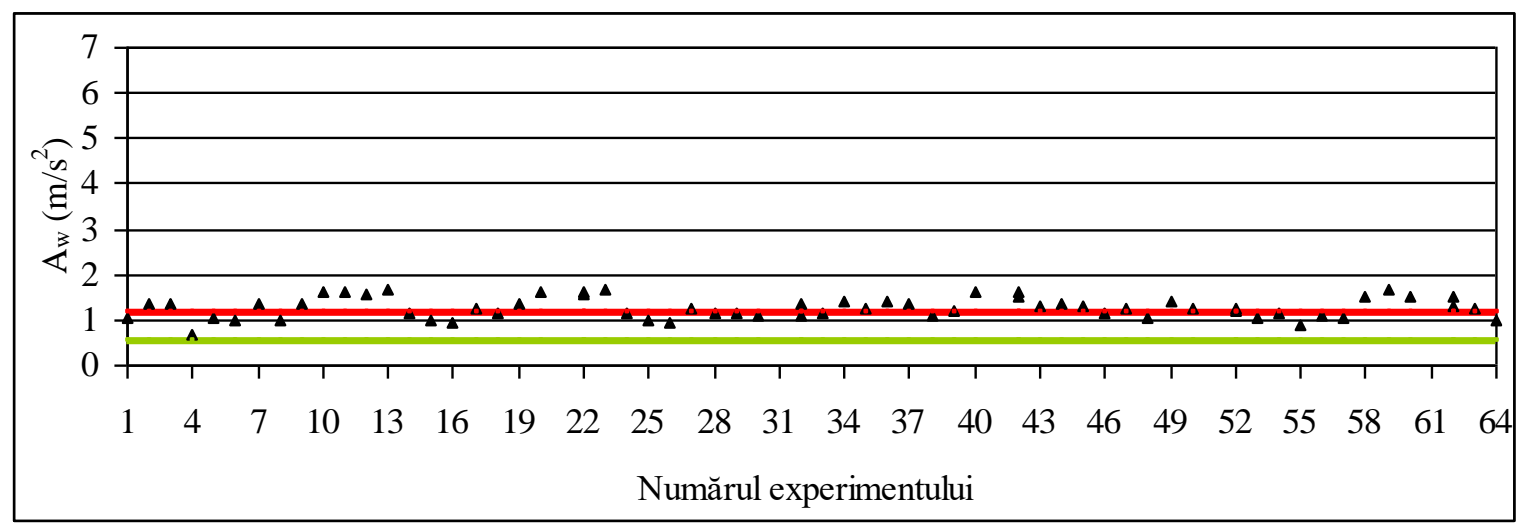

Fig. 10. Representation of the total acceleration r.m.s. weighted for the 2013 tractor $(\longrightarrow)$ the daily exposure action value standardised to an eight-hour

(-) the daily exposure limit value standardised to an eight-hour

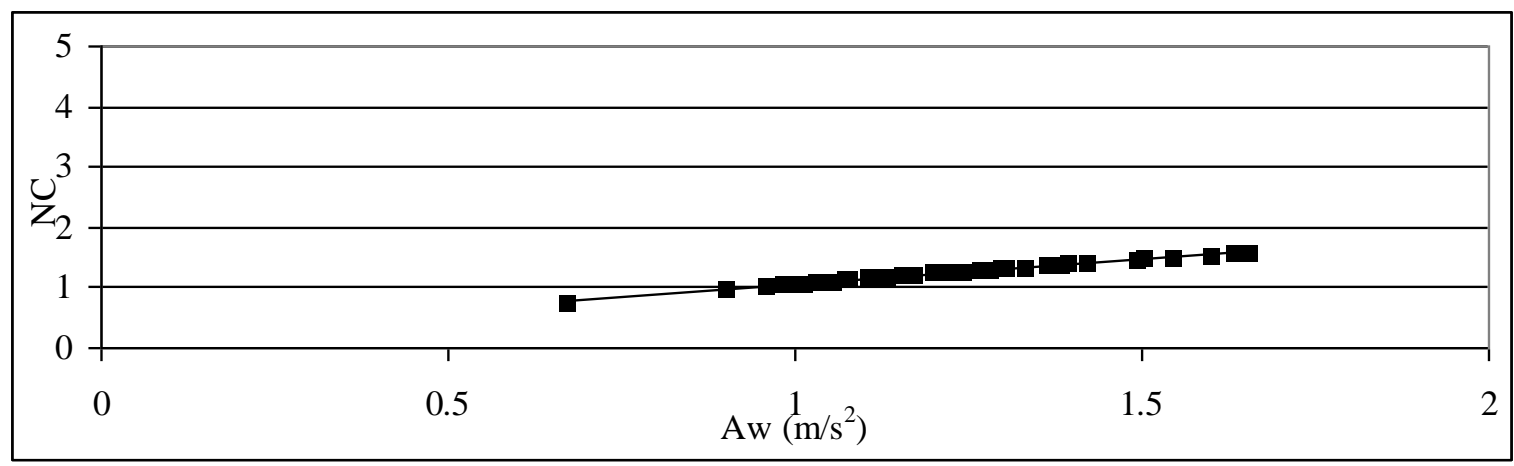

Fig. 11. Representation of the Comfort Note for the 2013 tractor

From Fig. 11 it can be seen that Comfort Note mentions values between 0.7457 and 1.5802 and, according to Tab. 3, if $A_{w}>2 \mathrm{~m} / \mathrm{s}^{2}$, the situation is between fairly uncomfortable and uncomfortable.

In this case, one can see that the values for Comfort Note line up along a line:

$$
\mathrm{NC}=0.8112 \cdot \mathrm{A}_{\mathrm{w}}+0.2531\left(\mathrm{R}^{2}=0.9976\right)
$$

Fig. 12 shows the spectral distribution of the measured noise for the 2013 tractor. The sliders are placed at $160 \mathrm{~Hz}$, where the sound level is $53 \mathrm{~dB}(\mathrm{~A})$ and at $10 \mathrm{kHz}$, where the sound level is 41.3 $\mathrm{dB}(\mathrm{A})$. For this frequency range, the average sound level is $65.9 \mathrm{~dB}(\mathrm{~A})$ lower than the lower exposure action values (Directive 2003/10/EC [26]). 


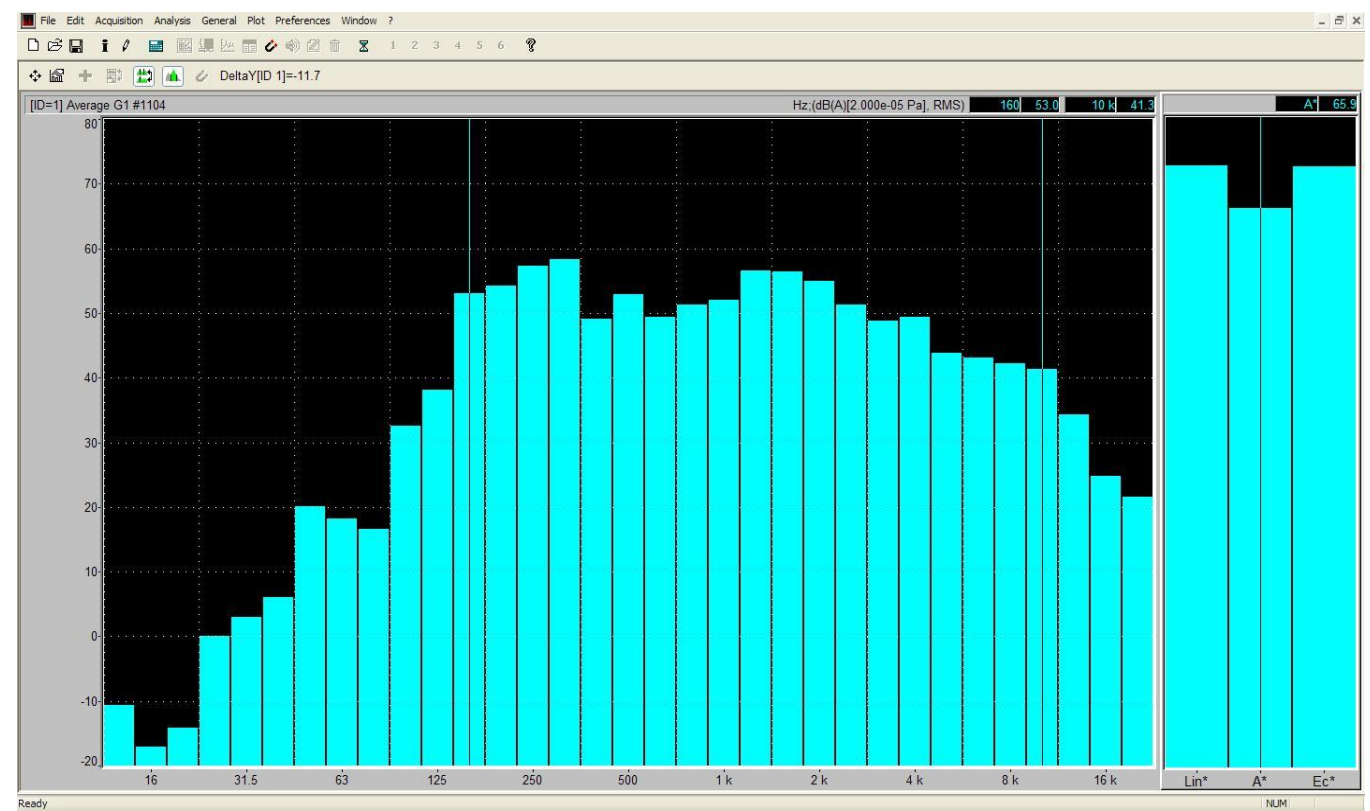

Fig. 12. Spectral sound analysis for the 2013 tractor

\section{CONCLUSIONS}

From the above-mentioned findings referring to those who operate the agricultural equipment under discussion, one conclusion can easily be drawn: the health condition of drivers using 1993 tractors is seriously affected (the comfort mark is "Extremely uncomfortable"),

The average sound level is $95.5 \mathrm{~dB}(\mathrm{~A})$, which far exceeds the exposure limit values $(87 \mathrm{~dB}(\mathrm{~A}))$. At this noise level, a worker can work a maximum of 1 hour, without experiencing health problems. In reality, these people are supposed to work as many as $12 \div 14$ hours a day at the height of the season, when there are agricultural works.

For this reason, the fleet of agricultural machines must be renewed, but this light is particularly difficult, given that their prices range from several tens of thousands of euros to hundreds of thousands of euros.

\section{References}

1. Hygge S., The interaction of noise and mild heat on cognitive performance and serial reaction time, Environment International 17(4) (1991) 229-234.

2. Witterseh T., Wyon D.P., Clausen G., The effects of moderate heat stress and open-plan office noise distraction on SBS symptoms and on the performance of office work, Indoor air 14(8) (2004) 30-40.

3. Pellerin N., Candas V., Effects of steady-state noise and temperature conditions on environmental perception and acceptability, Indoor air 14(2) (2004) 129-136, PMID: 15009419.

4. Bovenzi M., Ronchese F., Mauro M., A longitudinal study of peripheral sensory function in vibration-exposed workers, International archives of occupational and environmental health 84(3) (2011) 325-334.

5. Dupuis H., Zerlett G., The effects of whole-body vibration, Springer Science \& Business Media 2012, ISBN 978-3-540-16584-2.

6. Paddan G.S., Mansfield N.J., Arrowsmith C.I., Rimell A.N., King S.K., Holmes S.R., The influence of seat backrest angle on perceived discomfort during exposure to vertical wholebody vibration, Ergonomics 55(8) (2012) 923-936.

7. Picu M., The Qualitative Assesment of Emerging Risks to Workers Exposed to HAV, Journal of Materials Science and Engineering A 4(9) (2014) 315-320.

8. Picu M., A Dynamic Model of the Human Body in the Vertical Direction, Advanced Materials Research. Trans Tech Publications, Ltd. Vol. 837 (2014) 452-457. 
9. Picu M.E., Personality determination using vibrating movement parameters, Facta Universitatis, Series: Working and Living Environmental Protection 12(1) (2015) 49-61.

10. Picu M., A Study of Vertical Vibration Transmissibility by the Human Body, Applied Mechanics and Materials. Trans Tech Publications, Ltd. Vol. 325-326 (June 2013) 152-157.

11. Picu M., The transmission of vibration through car seats, International Journal of Modern Manufacturing Technologies 5(1) (2013) 87-90.

12. Picu M., A comparative study of the disconfort induced by vehicles to driver, International Journal of Modern Manufacturing Technologies Vol. IV No. 2 (2012) 61-66.

13. Village J., Trask C., Chow Y., Morrison J.B., Koehoorn M., Teschke K., Assessing whole body vibration exposure for use in epidemiological studies of back injuries: measurements, observations and self-reports, Ergonomics 55(4) (2012) 415-424.

14. Newell G.S., Mansfield N.J., Evaluation of reaction time performance and subjective workload during whole-body vibration exposure while seated in upright and twisted postures with and without armrests, International Journal of Industrial Ergonomics 38(5-6) (2008) 499-508.

15. Posea G., Geography of Romania, vol. V, The Romanian Plain, the Danube, the Dobrogea Plateau, the Romanian Black Sea Coast and the Continental Shelf, Romanian Academy Publishing House, Bucharest, 2005.

16. https://ro.wikipedia.org/wiki/C\%C3\%A2mpia_B\%C4\%83r\%C4\%83ganului

17. https://ro.wikipedia.org/wiki/C\%C3\%A2mpia_Br\%C4\%83ilei\#Geologie_\%C8\%99i_relief

18. H.G. 1876 of 22 December 2005 on the minimum safety and health requirements regarding the exposure of workers to the risks arising from vibration.

19. ISO 2631-1:1997, Mechanical vibration and shock - Evaluation of human exposure to wholebody vibration - Part 1: General requirements.

20. ISO 2631-4:2001, Mechanical vibration and shock - Evaluation of human exposure to wholebody vibration - Part 4: Guidelines for the evaluation of the effects of vibration and rotational motion on passenger and crew comfort in fixed-guideway transport systems.

21. ISO 2631-5:2018, Mechanical vibration and shock - Evaluation of human exposure to wholebody vibration - Part 5: Method for evaluation of vibration containing multiple shocks

22. ISO 5349-1:2001, Mechanical vibration - Measurement and evaluation of human exposure to hand-transmitted vibration - Part 1: General requirements.

23. ISO 5349-2:2001, Mechanical vibration - Measurement and evaluation of human exposure to hand-transmitted vibration - Part 2: Practical guidance for measurement at the workplace

24. ISO 8041-1:2017, Human response to vibration - Measuring instrumentation - Part 1: General purpose vibration meters.

25. ISO 8041-2:2021, Human response to vibration - Measuring instrumentation - Part 2: Personal vibration exposure meters.

26. Directive 2003/10/EC of the European Parliament and of the Council of 6 February 2003 on the minimum health and safety requirements regarding the exposure of workers to the risks arising from physical agents (noise).

27. Directive 2002/44/EC of the European Parliament and of the Council of 25 June 2002 on the minimum health and safety requirements regarding the exposure of workers to the risks arising from physical agents (vibration).

28. Genser A., Spielhofer R., Nitsche P., Kouvelas A., Ride comfort assessment for automated vehicles utilizing a road surface model and Monte Carlo simulations, Computer-Aided Civil and Infrastructure Engineering (nov. 2021) 1-19, ISSN 1093-9687. 